\title{
New host record for the Diplotriaena monticolae (Filariidae: Nematoda) from the thoracic cavity of Passer pyrrhonotus, Blyth 1845, (Passeridae: Passeriformes) in Larkana, Sindh, Pakistan
}

\author{
Irshad Chandio*, Ali Murtaza Dharejo, Muhammad Munif Khan and \\ Saima Naz \\ Department of Zoology, University of Sindh, Jamshoro-76080-Pakistan \\ *Corresponding author's email: irshadchandio14@gmail.com
}

Citation

Irshad Chandio, Ali Murtaza Dharejo, Muhammad Munif Khan and Saima Naz. New host record for the Diplotriaena monticolae (Filariidae: Nematoda) from the thoracic cavity of Passer pyrrhonotus, Blyth 1845, (Passeridae: Passeriformes) in Larkana, Sindh, Pakistan. Pure and Applied Biology. Vol. 8, Issue 1, pp580-584. http://dx.doi.org/10.19045/bspab.2018.700219

\begin{tabular}{llll}
\hline \hline Received: 10/10/2018 & Revised: 17/12/2018 & Accepted: 24/12/2018 & Online First: 29/12/2018 \\
\hline \hline
\end{tabular}

\section{Abstract}

The current examination was required to study nematodes of Sindh/Jungle Sparrow (Passer pyrrhonotus, Blyth 1845) from Larkana, Sindh, Pakistan. Fifteen Passer pyrrhonotus were examined for nematode parasites but only one bird has been found infected with five nematodes Diplotriaena monticolae Yamaguti, 1935 (02 $\widehat{\jmath}, 03$ ㅇ) belonging to family Filariidae; Nematodes were collected from the thoracic cavity of the Passer pyrrhonotus. Results of the present study revealed that Passer pyrrhonotus is a new host record for the Diplotriaena monticolae (Yamaguti, 1935). The present specimen Diplotriaena monticolae is accredited for the first time from Pakistan. Keywords: Diplotriaena monticolae; Larkana; Nematodes; Passer pyrrhonotus; Sindh/Jungle Sparrow

\section{Introduction}

Sindh Sparrow Passer pyrrhonotus (Passer pyrrhonotus Blyth, 1844), for the most part is called the Sindh /Jungle Sparrow or Rufousbacked Sparrow. Is a Passerine bird belongs to order Passeriformes, family Passeridae and is a member of the genus Passer. It is found in the Indus Valley region in South Asia. The Sindh Sparrow nourishes basically on the seeds of grasses and different plants, like; Polygonum plebeium. It might likewise rummage for creepy crawlies, for example, caterpillars, particularly to nourish nestlings. Inside its Indus Valley breeding range in Pakistan and western India, the Sindh Sparrow is patchily passed on in riverine and wetland attribute surroundings with prickly scour and tall grass [1].

During, the non-breeding season, some birds enter drier living spaces as they scatter short separations from their raising natural environment, or migrate to Pakistan and the extreme east of Iran [1].They are mainly 
granivorous in diet except when feeding young[2].

\section{Materials and methods}

For the present study 15 Passer pyrrhonotus were collected in January 2016 from Larkana District, Sindh, Pakistan, situated at the distance of $30 \mathrm{~km}$ from world famous site Mohen Jo Daro. Latitude 27.3243 ${ }^{\circ} \mathrm{N}$, Longitude $68.1357^{\circ} \mathrm{E}$ [3].

RLP-DZUSJ (Research Laboratory of Parasitology, Department of Zoology, University of Sindh, Jamshoro).

After anaesthetizing, birds were thoroughly examined for endo and ecto parasites.

Only one host was found infected with two male and three females of the Diplotriaena monticolae, but during process one male was damaged. Nematodes were removed from the body cavity with the help of a soft brush were relaxed, cleaned in $20 \%$ ethanol and killed in $70 \%$ ethanol and preserved in a mixture of glycerin and $70 \%$ ethanol (1:1 by volume). For morphological study nematodes were cleared in lactophenol and temporarily mounted for detailed study under a light microscope. Diagrams were made with the help of Camera Lucida and for snapshots; Olympus DP-12 digicam was used. All measurements are given in millimetres ( $\mathrm{mm}$ ) otherwise stated. Nematodes were identified with the help of relevant keys and latest literature available [4].

\section{Results}

Species: Diplotriaena monticola

Host Type: Sindh Sparrow Passer pyrrhonotus Blyth (Passeriformes: Passeridae).

The site of infection: Body cavity Locality: Larkana, Sindh, Pakistan

No. of specimen: 05 (02 $\lesssim \& 03$ 으) from a single host.

\section{Taxonomic standing}

Family: Filariidae Claus, 1885

Subfamily: Diplotriaeninae Skrjabin, 1916

Genus: Diplotriaena Railliet and Henry, 1909.

\section{Description}

The body of the worm is delicate and slenderically long, simple and without lips. A pair of chitinoid tridents is present in female whereas, in the male, it is small or inconspicuous and situated on the lateral side of the anterior end of esophagus. The buccal capsule is present. Oesophagus consisting of two parts; an anterior shorter, narrow muscular portion and a posterior longer, wider,glandular portion. Cervical alea is well developed and cervical papilla inconspicuous.

\section{Female}

Body length of the female worm is 0.887$1.604 \mathrm{~mm}$ and $0.029-0.038 \mathrm{~mm}$ in width. Tridents (Fig.1A) are $0.014-0.017 \mathrm{~mm}$ in length. The buccal capsule is present. Oesophagus overlapped by uterine tube hence not visible. Nerve ring is $0.057 \mathrm{~mm}$. The vulva (Fig.1B) is $0.05 \mathrm{~mm}$. The anus is subterminal. Eggs (Fig.3) are smooth, thickshelled, oval, 0.005-0.006 $\mathrm{mm}$ long and 0034-0.0038 mm wide.

\section{Male}

Body length of the male is $1 \mathrm{~mm}$ and $0.2 \mathrm{~mm}$ in width. Tridents are 0.012 in $\mathrm{mm}$. Buccal capsule and esophagus is present. Nerve ring is present. Excretory pore $0.017 \mathrm{~mm}$ from the anterior region. Five pairs of post-anal caudal papillae are present. Spicules are unequal, smooth anddissimilar. Spicule on the left side is about $0.091 \mathrm{~mm}$ (Fig.2A) and spicule on the right side is about $0.052 \mathrm{~mm}$ long (Fig.2B). Gubernaculum is absent. 
DiplotriaenamonticolaeYamaguti, 1935

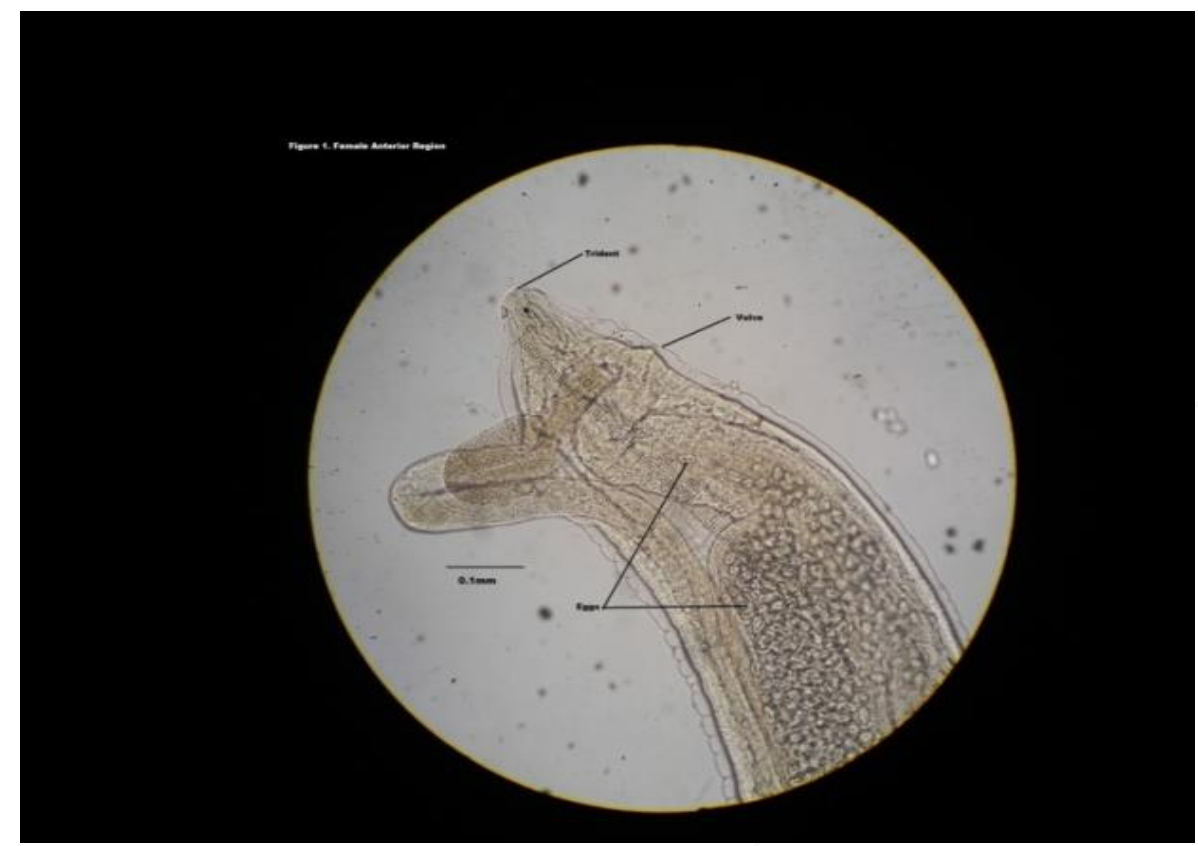

Figure1. Photograph of female anterior part showing: A. Tridents; B. Vulva; C. Eggs. (Scale bar: $0.1 \mathrm{~mm})$

DiplotriaenamonticolaeYamaguti, 1935

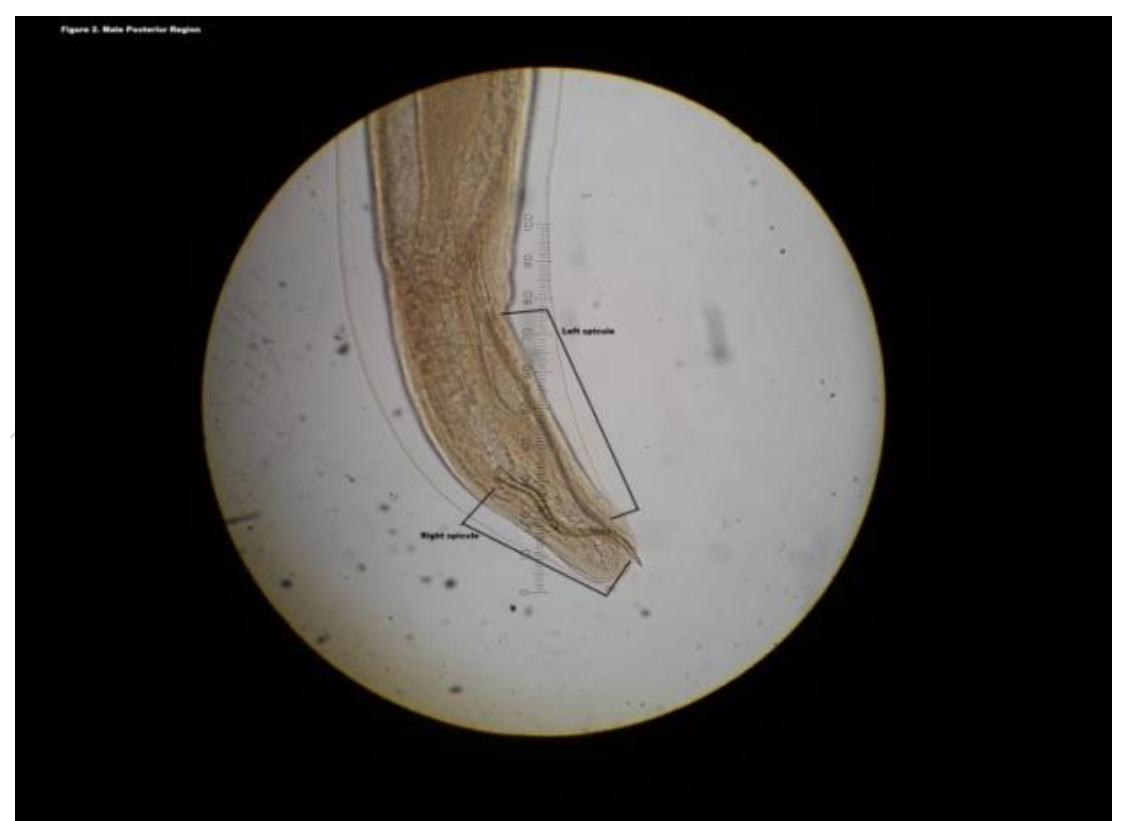

Figure 2. Photograph of Male posterior part showing: A. Left large spicule; B. Right small spicule. (Scale bar: 1mm) 
DiplotriaenamonticolaeYamaguti, 1935

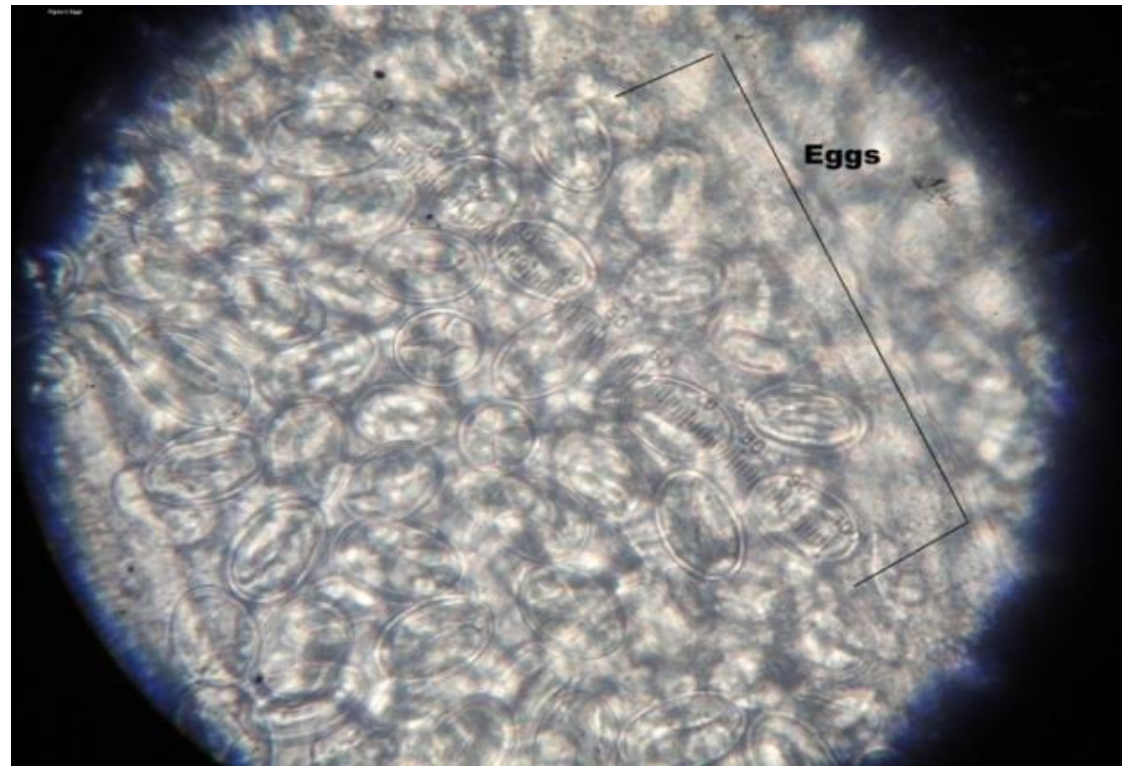

Figure 3. Photograph of Eggs showing: Well-embryonated eggs (Scale bar: $0.5 \mathrm{~mm}$ )

\section{Discussion}

The Genus Diplotriaena Railliet Henry, 1909 was erected to deal with the nematodes from birds. Until now more than sixty-one species of Genus Diplotriaena has been described from diverse flying creatures around the world. Diplotriaena passeri was reported recently from Pakistan from House Sparrow (Passer domesticus), Sindh Sparrow (Passer pyrrhonotus [5]. Previously from Pakistan Diplotriaena nochti Hoeppli et Hsu, 1929, from Sturnus roseus (Rosy Starling), Acridotheres ginginianus (Bank Myna), Diplotriaena Streptopelia from Streptopelia senegalensis (Laughing Dove) $[4,6]$. Other than Pakistan Diplotriaena monticolae Yamaguti, 1935 was reported from WhiteSpectacled Bulbul (Pycnonotus xanthopygos) from Turkey [7]. Previously this species was reported from Monticola solitaries from Japan [4].

\section{Conclusion}

Results from the present study determined that the present specimens have close resemblance with Diplotriaena moniticolae
Yamaguti, 1935 in all essential features hence identified as such. Passer pyrrhonotus is a new host record for the Diplotriaena monticolae (Yamaguti, 1935) and this species is accredited for the first time from Pakistan.

\section{Authors' contributions}

Conceived and designed the experiments: I Chandio \& AM Dharejo, Performed the experiments: I Chandio, Analyzed the data: I Chandio \& AM Dharejo, Contributed materials/ analysis/ tools: I Chandio AM Dharejo, MM Khan \& S Naz, Wrote the paper: I Chandio.

\section{Reference}

1. https://en.wikipedia.org/wiki/Sind_Sparr ow.

2. Roberts, Tom J. (1992). The Birds of Pakistan. Vol 2: Passeriformes: Pittas to Buntings. Oxford: Oxford University Press. ISBN 978-0-19-577405-4.

3. http://www.worldatlas.com/as/pk/sd/wher e-is-larkana.html.

4. Yamaguti, S (1961). Systema Helminthum. Vol. III. The Nematodes of 
Vertebrates, Pt. II \& I. Inter science Publishers, New York \& London, pp 1261. ISBN 184535721.

5. Chandio I, Dharejo AM, Naz S \& Khan MM (2015).New species of Genus Diplotriaena Railliet and Henry, 1909 (Filariidae: Nematoda) from Passer domesticus Linnaeus and $P$. pyrhonotus Blyth (Passeridae: Passeriformes) in
Jamshoro, Sindh, Pakistan. Turk Psikol Derg 39:265-9.

6. Bilquees FM \& Jahan N (1977). Helminth Parasites of Some Birds in Sindh Pakistan. Pak J Scient Ind Res 20: 26.

7. Yaman M \& Ayaz E (2007). Bir Arap Bulbulunde (Pycnonotus xanthopygos) Diplotriaena monticolae Yamaguty, 1935. (Fam: Filariidae) Olgusu. Turk Psikol Derg 31(3): 215-218. 